\title{
Willingness of Family Caregivers to Consent to Relative's Postmortem Examination that Die Suddenly in a Nigerian Tertiary Hospital
}

\author{
Samuel Anu Olowookere ${ }^{*}$, Adegboyega Adeleke Abiodun ${ }^{2}$, Joseph Gbenga \\ Omole $^{3}$, Akinwumi Oluwole Komolafe ${ }^{4}$, Akintunde Julius Olowookere ${ }^{5}$, \\ Emmanuel Akande $^{1}$, Ayodeji Babalola ${ }^{1}$, Oriyomi Sanni ${ }^{1}$, Joshua Ajala ${ }^{1}$, Thomas \\ Ifogah $^{1}$
}

\footnotetext{
OPEN ACCESS

Citation: Samuel Anu Olowookere, Adegboyega Adeleke Abiodun, Joseph Gbenga Omole, Akinwumi Oluwole Komolafe, Akintunde Julius Olowookere, Emmanuel Akande, Ayodeji Babalola, Oriyomi Sanni, Joshua Ajala, Thomas Ifogah. Willingness of Family Caregivers to Consent to Relative's Postmortem Examination that Die Suddenly in a Nigerian Tertiary Hospital. Ethiop J Health

2020;30(3):377.doi:http://dx.doi.org/10.431 4/ejhs.v30 i3.9.

Received: October 30, 2019

Accepted: December 30, 2019

Published: May 1, 2020

Copyright: (C2020 Olowookere S.A., et al. This is an open access article distributed under the terms of the Creative Commons Attribution License, which permits unrestricted use, distribution, and reproduction in any medium, provided the original author and source are credited. Funding: None

Competing Interests: The authors declare that this manuscript was approved by all authors in its form and that no competing interest exists.

Affiliation and Correspondence:

${ }^{1}$ Department of Community Health,

Obafemi Awolowo University, Ile-Ife,

Nigeria

${ }^{2}$ Department of Anatomy and Cell

Biology, Obafemi Awolowo

University, Ile-Ife, Nigeria

${ }^{3}$ Department of Physiological Sciences,

Obafemi Awolowo University, Ile-Ife,

Nigeria

${ }^{4}$ Department of Morbid Anatomy,

Obafemi Awolowo University, Ile-Ife,

Nigeria

${ }^{5}$ Accident and Emergency Department, Obafemi Awolowo University

Teaching Hospitals Complex, Ile-Ife, Nigeria

*Email: sanuolowookere@yahoo.com
}

\section{ABSTRACT}

BACKGROUND: Postmortem examination is necessary to diagnose the cause of sudden death, and family caregivers are expected to consent to this examination. This study assessed knowledge, attitude, practices and willingness of family caregivers to consent to postmortem examination of their relative if they die suddenly in a Nigerian tertiary hospital.

METHODS: Descriptive cross-sectional study of family caregivers of our patients that completed an interviewer administered semistructured questionnaire assessing their knowledge, attitude, practices and willingness to consent to postmortem examination of their relative if they die suddenly. Data were analyzed using descriptive and inferential statistics.

RESULTS: A total of 224 caregivers were interviewed. The mean age (SD) was 34.95 (11.74), ranging 22-75 years. They were parents (32.6\%), siblings (37.9\%), spouses (11.2\%) and other relatives (18.3\%). Only 17\% had adequate knowledge, $44.6 \%$ positive attitude and $11.2 \%$ good practices to postmortem examination of sudden death. The majority (75.9\%) would consent to postmortem examination of their relatives if they die suddenly. Sociodemographic variables associated with willingness to consent to postmortem examination after relative's sudden death include being male (AOR 3.61; 95\%CI 3.09-8.92; $p=0.001$ ), having tertiary education (AOR 4.83; 95\%CI 1.01-8.29; $p=0.034$ ), Christianity (AOR 2.59; 95\%CI 1.25-5.35; $p=0.010)$ and skilled worker (AOR 1.43; 95\%CI 1.33-3.80; $p=0.020$ ).

CONCLUSION: Some family caregivers would not consent to postmortem examination of their relatives when they die suddenly. Sensitization programs targeting family caregivers are necessary to increase knowledge and enhance prevention of sudden death as well as improve willingness to consent to postmortem examination when their relatives die suddenly.

KEYWORDS: Family caregivers, postmortem examination, consent, relatives 


\section{INTRODUCTION}

Sudden death is unexpected death in an apparently healthy individual $(1,2)$. The prevalence of sudden death continues to increase worldwide $(2,3)$. The cause of sudden death could vary, hence the need to conduct a postmortem examination in every case. Identifying the probable cause of death in apparently healthy individuals dying suddenly could enable the prevention of further deaths from this cause $(3,4)$.

A family caregiver can be defined as a family member that lives with the patient and is closely involved in their activity of daily living, healthcare, and relates socially with them. Most caregivers are genetically related to the patient sharing the same household and community with them. They provide mostly unpaid service to the patient and share in their sufferings $(5,6)$. They are affected physically, psychologically and socially when their relative dies. The suffering of the family caregiver could increase when somebody dies suddenly when they least expect. The cause of such death could be apparent while in some cases unknown $(6,7)$.

A patient who dies suddenly or brought in death is declared a coronal case whose death must be investigated by the pathologist. The postmortem examination could include anatomical, pathological and toxicological examination of the dead patient. In Nigeria, this postmortem investigation requires the consent and payment of a sum to the hospital by the family caregiver before the procedure is carried out. Since this payment is most often not waived and the family caregiver might not have the funds ready or may be unwilling to pay, this situation might further delay or prevent this investigation from being done leading to misunderstandings between the family caregiver and the hospital management. In cases where the suspected cause of death has public health or medico-legal implications, the dead body might not be released for burial until this procedure is done which leads to societal conflicts requiring immediate burial of the dead due to cultural, religious and other reasons (7-9).

Recent events worldwide, including Nigeria, have reported individuals and at times families dying at the same period from natural events such as flooding, house collapse, food poisoning, carbon monoxide poisoning, epidemics (such as cholera, yellow fever outbreaks) and death from criminal activities (such as armed robbery, kidnapping and banditry/Boko Haram activities). Also, the need for postmortem examination in death resulting from substance use especially in drugs eliminating memory of events which could include incidence of gang rape, suicide, parasuicide, and homicide $(1,3,9,10)$. Since it is a requirement for death certificate to be issued before burial, sudden deaths most of the time require extensive investigation on the probable cause or causes of death, hence, the need for this study.

This study assessed knowledge, attitude, and practices of family caregivers regarding postmortem examination in sudden death. Also, the study assessed their willingness to consent to postmortem examination of their relatives if they die suddenly in a Nigerian tertiary hospital.

\section{METHODS}

Study site: This study was conducted in Obafemi Awolowo University Teaching Hospitals Complex, Ile-Ife, Nigeria. The hospital is a 576-bed tertiary health centre, 200 kilometres northeast of Lagos and serves as a referral centre for the neighbouring states of Oyo, Kwara, Ondo, Ekiti, and Kogi. An average of 2 clinical/coroner postmortem examinations are performed daily in the hospital.

Study design: A descriptive cross-sectional study was employed.

Study population: The study population include family caregivers of patients attended to at the medical and surgical clinics, intensive care unit, emergency department and wards of the hospital.

Sample size calculation: A sample size of 250 was calculated with $8.7 \%$ family caregivers willing to consent to autopsy on their relatives and nonresponders taken into consideration $(11,12)$.

Inclusion criteria: The inclusion criteria were family caregivers of patients attended to at the medical and surgical clinics, intensive care unit, emergency department and wards of the hospital.

Exclusion criteria: Family caregivers who did not consent to the study were excluded.

Sampling technique: The family caregivers were consecutively recruited by five final year medical students who were trained on data collection.

Data collection: These family caregivers were approached for written consent after explaining the purpose of the study and requested to complete a

DOI: http://dx.doi.org/10.4314/ejhs.v30i3.9 
pre-tested interviewer administered questionnaire. This instrument contained questions on their sociodemographic characteristics, their knowledge of sudden death, its causes and prevention, attitude towards having postmortem examination on relative after sudden death, hindrances to postmortem examination of sudden death and willingness to consent to postmortem examination of relatives after sudden death. The questionnaire was prepared after adequate review of literature with face validity of the questionnaire done by the authors to ensure that it answered its set objectives. Pre-testing of the questionnaire was done among family caregivers not included in this study.

Ethical considerations: The ethical approval was obtained from the Ethics and Research Committee of the Obafemi Awolowo University Teaching Hospitals Complex, Ile-Ife, Nigeria. Participation was entirely voluntary, and confidentiality was ensured; codes, rather than participants' names, were used as personal identifiers, and the data were stored in a computer that was accessible only to the lead author.

\section{MEASURES}

Knowledge of sudden death and postmortem examination: Respondents were asked fifteen questions that assessed knowledge of sudden death, its causes, prevention and postmortem examination. Appropriate responses had scores of ' +1 ' while inappropriate responses had scores of ' 0 '. These scores were summated with mean score used as cut off point and those scoring equal to or above the mean having adequate knowledge and those scoring below having inadequate knowledge.

Attitude towards sudden death and postmortem examination: Participants were asked nine questions on their attitude towards occurrence of sudden death and postmortem examination. For family caregivers that had no knowledge of postmortem examination, the procedure was explained before proceeding with further questioning. Statements were either positively or negatively phrased with response to each question rated on the Likert scale ranging from 'strongly agree' to 'strongly disagree'. The most appropriate responses had scores of ' +4 ' while the least inappropriate responses had scores of ' 0 '. These scores were summated with mean score used as cut off point and those scoring equal to or above the mean having positive attitude and those scoring below having negative attitude.

Practice regarding sudden death, postmortem examination and willingness to consent to postmortem examination of relatives that die suddenly: Participants responded to eight questions on their practice regarding sudden death, postmortem examination and willingness to consent to postmortem examination of their relatives if they die suddenly. Appropriate responses had scores of ' +1 ' while inappropriate responses had scores of ' 0 '. These scores were summated with mean score used as cut off point and those scoring equal to or above the mean having good practice and those scoring below having poor practice.

Data analysis: Data obtained were analyzed using SPSS version 16. Simple descriptive and inferential statistics were done. Test of significance was conducted using appropriate statistical methods. Bivariate chi-square test and multivariate logistic regression analysis were performed on family caregivers' characteristics and willingness to consent to postmortem examination of their relatives if they die suddenly. Variables in the bivariate test with $p$-value $<0.2$ were included in the multivariate model with odd ratio (OR) and $95 \%$ CI presented and used as measures of the strength of association. Significant level was put at $\mathrm{p}<0.05$.

\section{RESULTS}

Demographic data: A total of 224 caregivers with completed questionnaire were analyzed (response rate $89.6 \%$ ). Their mean age (SD) was 34.95 (11.74), ranging 22-75 years. They were parents $(32.6 \%)$, siblings $(37.9 \%)$, spouses $(11.2 \%)$ and other relatives $(18.3 \%)$. Most family caregivers had tertiary education $(73.2 \%)$, were females $(69.6 \%)$, married (54\%), Christians (76.8\%), skilled workers $(56.7 \%)$ and Yoruba (85.7\%), a Nigerian tribe (Table 1).

DOI: http://dx.doi.org/10.4314/ejhs.v30i3.9 
Table 1: Socio-demographic characteristics of Family caregivers

\begin{tabular}{|c|c|c|}
\hline Variable & Frequency $(n=224)$ & $\%$ \\
\hline \multicolumn{3}{|l|}{ Family caregiver } \\
\hline Father & 17 & 7.6 \\
\hline Mother & 56 & 25.0 \\
\hline Brother & 50 & 22.3 \\
\hline Sister & 35 & 15.6 \\
\hline Cousin & 25 & 11.2 \\
\hline Nephew & 16 & 7.1 \\
\hline Spouse & 25 & 11.2 \\
\hline \multicolumn{3}{|l|}{ Age group (years) } \\
\hline $22-29$ & 105 & 46.9 \\
\hline$\geq 30$ & 119 & 53.1 \\
\hline \multicolumn{3}{|l|}{ Gender } \\
\hline Male & 68 & 30.4 \\
\hline Female & 156 & 69.6 \\
\hline \multicolumn{3}{|l|}{ Level of education } \\
\hline Primary & 12 & 5.4 \\
\hline Secondary & 48 & 21.4 \\
\hline Tertiary & 164 & 73.2 \\
\hline \multicolumn{3}{|l|}{ Marital status } \\
\hline Single & 95 & 42.4 \\
\hline Married & 121 & 54.0 \\
\hline Divorced & 8 & 3.6 \\
\hline \multicolumn{3}{|l|}{ Religion } \\
\hline Islam & 52 & 23.2 \\
\hline Christianity & 172 & 76.8 \\
\hline \multicolumn{3}{|l|}{ Ethnicity } \\
\hline Igbo & 32 & 14.3 \\
\hline Yoruba & 192 & 85.7 \\
\hline \multicolumn{3}{|l|}{ Occupation } \\
\hline Unskilled worker & 97 & 43.3 \\
\hline Skilled worker & 127 & 56.7 \\
\hline
\end{tabular}

Figure 1 reports the knowledge, attitude and practices regarding postmortem examination of sudden death. It shows that only $17 \%$ had adequate knowledge, $44.6 \%$ had positive attitude and $11.2 \%$ had good practices regarding postmortem examination of somebody that dies suddenly.

Table 2 reports the knowledge, attitude, practices and willingness of family caregivers to consent to postmortem examination on relatives that die suddenly. All family caregivers have heard of sudden death with cardiac arrest reported as the commonest cause by the majority $(65.2 \%)$. Threequarters knew that sudden death is preventable with routine medical checkup seen by most $(70.8 \%)$ as the commonest way to prevent it. Only $16 \%$ of the respondents had done medical checkup in the previous year. However, most respondents $(88.4 \%)$ agreed that sudden death also has a spiritual cause with the majority agreeing that postmortem examination done after sudden death is basically for research purpose $(94.5 \%)$ while some respondents saw it as unnecessary mutilation of the dead body $(54 \%)$. Some respondents agreed that their culture (50.4\%) and religion (45.5\%) do not support postmortem examination with $67.4 \%$ agreed that it is informative to do postmortem examination in sudden death. Although the majority $(90.6 \%)$ had heard of somebody dying suddenly with reported circumstances of death including person slumped and died (46.3\%), died while sleeping (39.9\%) and died in road traffic accident (13.8\%). Only $5.9 \%$ of those that died suddenly had postmortem examination with their family caregivers not aware of the actual cause of death. Five (2.2\%) family caregivers ever consented to postmortem examination of their relatives that died suddenly with only one $(20 \%)$ receiving the postmortem report. Identified hindrances to postmortem examination of sudden death were misconceptions about the examination (84.4\%), seeing it as a waste of time $(70.1 \%)$, religious $(65.2 \%)$ and cultural $(62.9 \%)$ beliefs, payment for the examination $(48.7 \%)$ and age of the dead (36.1\%). The majority (75.9\%) would consent to postmortem examination of their relatives that die suddenly while $85.3 \%$ would support other people to consent to postmortem examination of their relatives that die suddenly. 


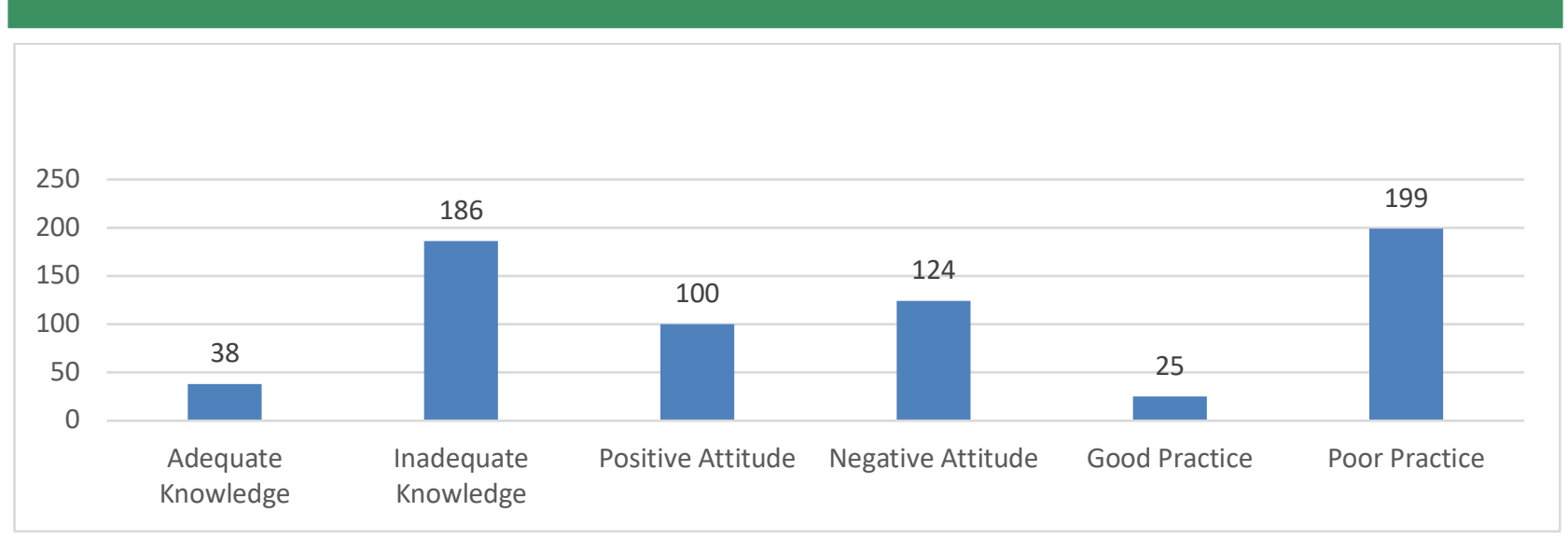

Figure 1: Knowledge, attitude and practices regarding postmortem examination of sudden death

Table 2: Knowledge, attitude, practices and willingness of family caregivers to consent to postmortem examination on relatives that die suddenly.

\begin{tabular}{|c|c|c|}
\hline Variable & Frequency & $\%$ \\
\hline \multicolumn{3}{|l|}{ Knowledge } \\
\hline Ever heard of sudden death (Yes) & 224 & 100.0 \\
\hline \multicolumn{3}{|l|}{ * Common causes of sudden death } \\
\hline Cardiac arrest & 146 & 65.2 \\
\hline Asthmatic attack & 43 & 19.2 \\
\hline Road traffic accident & 35 & 15.6 \\
\hline Food poisoning & 32 & 14.3 \\
\hline Suicide & 29 & 12.9 \\
\hline Substance abuse & 23 & 10.3 \\
\hline \multicolumn{3}{|l|}{ Sudden death can be prevented } \\
\hline Yes & 168 & 75.0 \\
\hline No & 56 & 25.0 \\
\hline \multicolumn{3}{|l|}{ *Ways to prevent sudden death $(\mathrm{n}=168)$} \\
\hline Regular medical check up & 119 & 70.8 \\
\hline Prayer & 98 & 58.3 \\
\hline Adequate exercise & 31 & 18.5 \\
\hline Keeping to good diet & 25 & 14.9 \\
\hline Visit a hospital for medical checkup in the last 12 months (yes) & 36 & 16.1 \\
\hline \multicolumn{3}{|l|}{ Reason for medical checkup $(n=36)$} \\
\hline Require to travel & 11 & 30.6 \\
\hline Require at school & 9 & 25.0 \\
\hline Require for national service & 8 & 22.2 \\
\hline Require for pre-employment & 8 & 22.2 \\
\hline \multicolumn{3}{|l|}{ Attitude } \\
\hline \multicolumn{3}{|l|}{ Sudden death could have spiritual cause } \\
\hline Agree & 198 & 88.4 \\
\hline Disagree & 26 & 11.6 \\
\hline \multicolumn{3}{|l|}{ Postmortem examination is unnecessary mutilation of the dead body } \\
\hline Agree & 121 & 54.0 \\
\hline Disagree & 103 & 46.0 \\
\hline \multicolumn{3}{|l|}{ Postmortem examination is done for research purpose } \\
\hline Agree & 212 & 94.5 \\
\hline Disagree & 12 & 5.5 \\
\hline
\end{tabular}

DOI: http://dx.doi.org/10.4314/ejhs.v30i3.9 
Table 2. Continued...

\begin{tabular}{|c|c|c|}
\hline \multicolumn{3}{|c|}{ My culture does not support postmortem examination } \\
\hline Agree & 113 & 50.4 \\
\hline Disagree & 111 & 49.6 \\
\hline \multicolumn{3}{|c|}{ My religion does not support postmortem examination } \\
\hline Agree & 102 & 45.5 \\
\hline Disagree & 122 & 54.5 \\
\hline \multicolumn{3}{|c|}{ It is informative to do postmortem examination in sudden death } \\
\hline Agree & 151 & 67.4 \\
\hline Disagree & 73 & 32.6 \\
\hline \multicolumn{3}{|l|}{ Practices/willingness } \\
\hline \multicolumn{3}{|l|}{ Heard of somebody dying suddenly } \\
\hline Yes & 203 & 90.6 \\
\hline No & 21 & 9.4 \\
\hline \multicolumn{3}{|l|}{ Circumstances of the sudden death $(n=203)$} \\
\hline Person slumped and die & 94 & 46.3 \\
\hline Die while sleeping & 81 & 39.9 \\
\hline Road traffic accident & 28 & 13.8 \\
\hline \multicolumn{3}{|l|}{ Postmortem examination was done $(n=203)$} \\
\hline Yes & 12 & 5.9 \\
\hline No & 191 & 94.1 \\
\hline Postmortem examination findings (don't know) & 12 & 100.0 \\
\hline \multicolumn{3}{|c|}{ Ever consent to postmortem examination of a relative that die suddenly } \\
\hline Yes & 5 & 2.2 \\
\hline No & 219 & 97.8 \\
\hline \multicolumn{3}{|l|}{ Received postmortem examination report $(n=5)$} \\
\hline Yes & 1 & 20.0 \\
\hline No & 4 & 80.0 \\
\hline \multicolumn{3}{|c|}{ *Hindrances to postmortem examination of sudden death $(n=224)$} \\
\hline Misconceptions about the examination & 189 & 84.4 \\
\hline See postmortem examination as a waste of time & 157 & 70.1 \\
\hline Religious belief & 146 & 65.2 \\
\hline Cultural practices & 141 & 62.9 \\
\hline Payment for the postmortem examination & 109 & 48.7 \\
\hline Age of the dead relative & 81 & 36.1 \\
\hline \multicolumn{3}{|c|}{ Will consent to postmortem examination in sudden death } \\
\hline Yes & 170 & 75.9 \\
\hline No & 54 & 24.1 \\
\hline \multicolumn{3}{|c|}{ Will support other people to consent to postmortem examination in sudden death } \\
\hline Yes & 191 & 85.3 \\
\hline No & 33 & 14.7 \\
\hline
\end{tabular}

*Multiple response

Table 3 shows the relationship between sociodemographic variables and willingness to consent to postmortem examination after relative's sudden death. A higher proportion of the parents, spouses and siblings would consent to postmortem examination. Other significant variables include being male, skilled worker, Christian, and having tertiary education.

Table 4 reports the logistic regression analysis of sociodemographic variables associated with willingness to consent to postmortem examination after relative's sudden death. Sociodemographic variables associated with willingness to consent to postmortem examination after relative's sudden death include being male (AOR 3.61; 95\% CI 3.09-8.92; $\mathrm{p}=0.001$ ), having tertiary education (AOR 4.83; 95\%CI 1.01-8.29; $\mathrm{p}=0.034$ ), Christian (AOR 2.59; $95 \%$ CI 1.25-5.35; $\mathrm{p}=0.010$ ) and skilled worker (AOR 1.43 ; $95 \%$ CI $1.33-3.80 ; \mathrm{p}=0.020$ ).

DOI: http://dx.doi.org/10.4314/ejhs.v30i3.9 
Table 3: Relationship between sociodemographic variables and willingness to consent to postmortem examination after relative's sudden death.

\begin{tabular}{|c|c|c|c|}
\hline \multirow[t]{2}{*}{ Variable } & \multirow[b]{2}{*}{ Yes (\%) } & Willingness & \multirow[t]{2}{*}{ Test statistics } \\
\hline & & No $(\%)$ & \\
\hline \multicolumn{4}{|l|}{ Family caregiver } \\
\hline Father & $10(58.8)$ & $7(41.2)$ & $50.095 ; 0.0001$ \\
\hline Mother & $36(64.3)$ & $20(35.7)$ & \\
\hline Brother & $49(98.0)$ & $1(2.0)$ & \\
\hline Sister & $28(80.0)$ & $7(20.0)$ & \\
\hline Cousin & $14(56.0)$ & $11(44.0)$ & \\
\hline Nephew & $8(50.0)$ & $8(50.0)$ & \\
\hline Spouse & $25(100.0)$ & $0(0)$ & \\
\hline \multicolumn{4}{|l|}{ Age group (years) } \\
\hline $22-29$ & $84(80)$ & $21(20)$ & $1.822 ; 0.177$ \\
\hline$\geq 30$ & $86(72.3)$ & $33(27.7)$ & \\
\hline \multicolumn{4}{|c|}{ Highest level of education } \\
\hline Primary & $6(50.0)$ & $6(50.0)$ & $10.181 ; 0.006$ \\
\hline Secondary & $31(64.6)$ & $17(35.4)$ & \\
\hline Tertiary & $133(81.1)$ & $31(18.9)$ & \\
\hline \multicolumn{4}{|l|}{ Gender } \\
\hline Male & $67(98.5)$ & $1(1.5)$ & Fisher's $p=0.0001$ \\
\hline Female & $103(66.0)$ & $53(34)$ & \\
\hline \multicolumn{4}{|l|}{ Marital status } \\
\hline Not married & $82(79.6)$ & $21(20.4)$ & $1.441 ; 0.230$ \\
\hline Currently married & $88(72.7)$ & $33(27.3)$ & \\
\hline \multicolumn{4}{|l|}{ Occupation } \\
\hline Skilled worker & $104(81.9)$ & $23(18.1)$ & $5.765 ; 0.019$ \\
\hline Unskilled worker & $66(68.0)$ & $31(32.0)$ & \\
\hline \multicolumn{4}{|l|}{ Religion } \\
\hline Islam & $31(59.6)$ & $21(40.4)$ & $9.807 ; 0.002$ \\
\hline Christianity & $139(80.8)$ & $33(19.2)$ & \\
\hline \multicolumn{4}{|l|}{ Ethnicity } \\
\hline Igbo & $31(96.9)$ & $1(3.1)$ & Fisher's $\mathrm{p}=0.001$ \\
\hline Yoruba & $139(72.4)$ & $53(27.6)$ & \\
\hline
\end{tabular}

Table 4: Logistic regression analysis of sociodemographic variables associated with willingness to consent to postmortem examination after relative's sudden death.

\begin{tabular}{lll}
\hline Variable & COR; 95\%CI; p-value & AOR; 95\%CI; p-value \\
\hline Age group (years) & $1.54 ; 1.82-2.87 ; 0.079$ & $1.59 ; 1.10-6.10 ; 0.029$ \\
$22-29$ & 1 & 1 \\
$\begin{array}{l}\geq 30 \text { (ref.) } \\
\text { Gender }\end{array}$ & $3.48 ; 3.26-9.29 ; 0.001$ & $3.61 ; 3.09-8.92 ; 0.001$ \\
Male & 1 & 1 \\
Female (ref.) & 1 & 1 \\
Highest level of education & $1.82 ; 0.51-6.54 ; 0.356$ & $1.25 ; 0.23-1.33 ; 0.183$ \\
$\begin{array}{l}\text { Primary (ref.) } \\
\text { Secondary }\end{array}$ & $4.29 ; 1.30-14.21 ; 0.017$ & $4.83 ; 1.01-8.29 ; 0.034$ \\
Tertiary & 1 & 1 \\
Religion & $2.85 ; 1.46-5.58 ; 0.002$ & $2.59 ; 1.25-5.35 ; 0.010$ \\
Islam (ref.) & & \\
Christianity & $2.12 ; 1.14-3.95 ; 0.018$ & $1.43 ; 1.33-3.80 ; 0.020$ \\
Occupation & 1 & 1 \\
Skilled worker & & \\
Unskilled worker (ref.) & &
\end{tabular}

DOI: http://dx.doi.org/10.4314/ejhs.v30i3.9 


\section{DISCUSSION}

This study assessed the willingness of family caregivers to consent to postmortem examination of their relatives if they die suddenly in a Nigerian tertiary hospital. It reported that some caregivers would not consent to postmortem examination if their relatives die suddenly. Prior studies had reported falling rates of postmortem examination due to sociocultural reasons and religious beliefs (13-17). In order to increase consent for postmortem examination especially in sudden death, it will be necessary to create awareness about this procedure that will unravel the cause of death which could further prevent future death in the family, community or population.

This study reported that the majority of the family caregivers had inadequate knowledge, negative attitude and poor practices towards postmortem examination when somebody dies suddenly. Despite inadequate knowledge, all family caregivers were aware of sudden death with the majority associating the cause with cardiac arrest. Several studies have reported this to be the case in sudden death worldwide (1-4). This awareness reflects the high level of formal education of our respondents as the majority had tertiary education. However, their recommendation of regular medical checkup to prevent sudden death did not correlate with their practice as the minority have undergone such checkup in the previous year. This implies that strategies to improve family caregivers' knowledge, attitude and practices, including undergoing routine medical checkup, to avoid early death from preventable causes should be put in place (17-19).

Most respondents reported spiritual cause as a cause of sudden death. This population showed high level of spirituality as all our respondents identified with a religious group. Hence, the interactions between illness, disease, death and spirituality might be difficult to separate as most religions and their adherents tend to interrelate them. Even the World Health Organization includes spiritual wellbeing as essential for good health $(20,21)$.

The attitude of some respondents toward postmortem examination of sudden death was positive while some respondents' attitude was negative. For instance, while most respondents considered postmortem examination after sudden death as an academic and research exercise that would unravel the cause of death which might assist in preventing further deaths, some respondents saw it as mutilation of the dead body. Although the majority saw postmortem examination in sudden death as informative, some respondents agreed that their culture and religious beliefs were against it. Several studies have reported differing findings (2123). This finding further implies that awareness creation is important targeting community and religious leaders on prevention of sudden death and giving consent to postmortem examination when community members or religious adherents die suddenly.

Most respondents had heard of somebody who died suddenly with circumstances of death including a person slumped and died, died during sleep and road traffic accident. This implies that sudden death is becoming common which shows the urgency in putting in place strategies in controlling and preventing its occurrences. The reported low proportion of people that die suddenly being investigated through postmortem examination shows the reason to create awareness on need for this procedure to prevent more sudden deaths $(24,25)$.

Also, very few family caregivers ever consented to postmortem examination of their relatives that died suddenly with only one receiving the postmortem report. The lack of feedback to family caregivers on the cause of death of their relatives could hamper future consent to such procedure, hence the need for those concerned to always give comprehensive feedback, including necessary steps to prevent future sudden death. If adequate feedback is given in all cases of sudden death after postmortem examination, it will remove hindrances to this procedure (25-27). The issue of payment for this procedure could be waived by government or the concerned hospital management when relatives have no money to pay or when there is no relative to take responsibility for payment to prevent delay in conducting the procedure. This will further increase the proportion of family caregivers that will consent or encourage others to consent to this procedure when required.

This study shows that the parents, spouses and siblings were willing to consent to postmortem examination of their relatives that die suddenly.

DOI: http://dx.doi.org/10.4314/ejhs.v30i3.9 
Also, being male, Christian, having tertiary education and being a skilled worker were sociodemographic factors associated with willingness to consent to postmortem examination of their relatives that die suddenly. These findings could be explained by the cultural and religious practices of the respondents with decision making lying with the male sex and those employed $(27,28)$. In Nigeria, Christians usually delay burial while Muslims bury their dead immediately which could partly explain this study findings (24).

This study is limited by its cross-sectional study design and being self-reported but it obtained information which could be very useful to policy makers and hospital managers. Some family caregivers would not consent to postmortem examination of their relatives when they die suddenly. Sensitization programs targeting family caregivers is necessary to increase awareness and enhance prevention of sudden death and improve willingness to consent to postmortem examination of their relatives who die suddenly.

\section{REFERENCES}

1. Pelemo OE, Sabageh D, Komolafe AO, Sabageh AO, Odesanmi WO. An autopsy review of sudden unexpected natural deaths in a suburban Nigerian population. Population Health Metrics. 2014; 12(26): 1-6.

2. Yener Z, Celbis O. Autopsy in sudden cardiac deaths. Annals of Medical Research. 2018; 25(2): 299-304.

3. Lanjewar DN, Sheth NS, Lanjewar SD, Wagholikar UL. Analysis of causes of death as determined at autopsy in a single institute, the Grant Medical College and Sir J.J. Hospital, Mumbai, India, between 1884 and 1966 a retrospective analysis of 13024 autopsies in adults. Arch Pathol Lab Med. 2019: 1-6.

4. Lorpocaro CG, Tester DJ, Maleszewski JJ, Kruisselbrink T, Ackerman MJ. Confirmation of cause and manner of death via a comprehensive cardiac autopsy including whole exome next-generation sequencing. Arch Pathol Lab Med. 2014; 138: 1083-1089.

5. Pharr JR, Francis CD, Terry C, Clark MC. Culture, Caregiving, and Health: Exploring the Influence of Culture on Family Caregiver
Experiences. ISRN Public Health. 2014; 1-8. http://dx.doi.org/10.1155/2014/689826

6. Olowookere SA, Badmus SA, Laoye O, Ijadunola MY, Hassan M. Burden of family caregivers of ophthalmic patients in a university teaching hospital in south-west Nigeria. Malawi Medical Journal. 2019; 31: 39-44.

7. Perner A, Köhler N, Brähler E, Götze H. Quality of life and satisfaction of family caregivers in palliative care - results of postmortem interviews with bereaved family members. Z Psychosom Med Psychother 2012; 58: 267-281

8. Mjörnheim B, Rosendahl A, Eriksson LC, Takman C. Attitudes of nurses and physicians about clinical autopsy in neonatal and adult hospital care: A survey in Sweden. Nurs Res. 2015; 64(4): 264-71.

9. Pacheco MC, Reed RC. Pathologist effort in the perfomance of fetal, perinatal and pediatric autopsies a survey of practice. Arch Pathol Lab Med. 2017; 141: 209-214.

10. Malami SA, Mohammed A. Autopsy practice in northern Nigeria. The Nigerian Journal of Surgical Research. 2002; 4(3): 119-121.

11. Kish L. Survey sampling. John Wiley and Sons, N.Y. 1965.

12. Oluwasola OA, Fawole OI, Otegbayo AJ, Ogun GO, Adebamowo CA, Bamigboye AE. The autopsy knowledge, attitude, and perceptions of doctors and relatives of the deceased. Arch Pathol Lab Med. 2009;133(1):78-82.

13. Agboola AOJ, Izegbu MC, Oyebadejo TY. Necropsy request behaviour of clinicians: A study from a University Teaching Hospital in Nigeria. Pakistan J Med Sci. 2009; 25(4): 6505.

14. Geller SA. Who will do my autopsy? Arch Pathol Lab Med. 2015; 139: 578-580.

15. Hebert TM, Maleki S, Vasovic LV, Arnold JL, Steinberg JJ, Prystowsky MB. A tean-based approach to autopsy education. Integrating anatomic and clinical pathology at the rotation level. Arch Pathol Lab Med. 2014; 138: 322327.

DOI: http://dx.doi.org/10.4314/ejhs.v30i3.9 
16. Keys E, Brownlee C, Ruff M, Baxter C, Steele L, Green FHY. How well do we communicate autopsy findings to next of kin? Arch Pathol Lab Med. 2008; 132: 66-71.

17. Goldman BI, Reviving the hospital autopsy. Arch Pathol Lab Med. 2016; 140: 503-504.

18. Kaschula ROC. The pediatric autopsy in Africa. Arch Pathol Lab Med. 2013; 137: 756766.

19. Turnbull A, Osborn M, Nicholas N. Hospital autopsy: Endangered or extinct? J Clin Pathol. 2015; 68(8): 601-604.

20. Searight HR, Gafford J. Cultural diversity at the end of life: issues and guidelines for the family physician. American Family Physician. 2005; 71: 515-522.

21. Yun YH, Kwon YC, Lee MK, Lee WJ, Jung KH, Do YR, Kim S, Heo DS, Choi JS, Park SY. Experiences and attitudes of patients with terminal cancer and their family caregivers toward the disclosure of terminal illness. Journal of Clinical Oncology. 2010; 28: 19501957.

22. Mengelers AMHJ, Bleijievens MHC, Verbeek H, Capezuti E, Tan FES, Hamers JPH.
Professional and family caregivers' attitude towards involuntary treatment in communitydwelling people with dementia. Journal of Advance Nursing. 2019; 75: 96-107.

23. Ekanem VJ, Akhigbe KO. Attitude of Nigerian medical students towards autopsy. Turk J Med Sci.2006; 36: 51-56.

24. Atanda A, Umar A, Yusuf I, Imam M, Sule A. Autopsy and religion: A review of the literature. Sahel Med J. 2016;19(3):119.

25. van den Tweel JG, Wittekind C. The medical autopsy as quality assurance tool in clinical medicine: dreams and realities. Virchows Arch. 2016; 468(1): 75-81.

26. Krywanczyk A, Mount S. In defence of academic autopsy. Arch Pathol Lab Med. 2018; 142: 157-158.

27. Laposata M. A new kind of autopsy for the $21^{\text {st }}$ century medicine. Arch Pathol Lab Med. 2017; 141(7): 887-888.

28. Komolafe AO, Adefidipe AA, Akinyemi HAM OO. Medical Errors Detected at the Autopsy: A Prelude to Avoiding Malpractice Litigations. $J$ Adv Med Med Res. 2018;27(7):1-8. 